\section{Light Delays Germination of Alkali Sacaton}

\section{O. D. KNIPE}

Associate Plant Ecologist, Rocky Mountain Forest and Range Experiment Station, 1 Albuquerque, New Mexico.

\section{Highlight}

Exposure of alkali sacaton seeds to light for a few seconds after imbibition delayed germination $24 \mathrm{hr}$, exposure for 9 to $13 \mathrm{hr}$ delayed germination $28 \mathrm{hr}$, exposure for more than $13 \mathrm{hr}$ delayed germination $72 \mathrm{hr}$, and continuous exposure reduced germination $40 \%$.

In previous studies on factors affecting the germination of alkali sacaton (Sporobolus airoides Torr.), the growth chamber was programmed for $8 \mathrm{hr}$ in light and 16 hr in darkness (Knipe, 1967; 1969). These tests were started at 8:00 AM at the start of the light period.

\footnotetext{
${ }^{1}$ Forest Service, U.S. Department of Agriculture, with central headquarters maintained at Fort Collins in cooperation with Colorado State University; author is located at Albuquerque in cooperation with the University of New Mexico. Research reported here was conducted in cooperation with the Bureau of Land Management, U.S. Department of the Interior. It is extracted from a dissertation completed in partial fulfillment for the Ph.D. in Range Management, Department of Watershed Management, University of Arizona. Received May 5, 1970; accepted for publication July 3, 1970.
}

Seeds exposed to light during the first $8 \mathrm{hr}$ of each test showed no appreciable germination until about the 48th hr. On one occasion when a test was started at 4:00 PM, the time corresponding to the start of the 16-hr dark period, a considerable number of seeds germinated by the 24th hr. This indicated that alkali sacaton is negatively photoblastic, at least during the early or pregermination stage.

The purpose of this study, therefore, was to determine the effect of light on germination of alkali sacaton.

\section{Literature Review}

Prior to the turn of the century, photoblastism was thought to be an isolated phenomenon restricted to very few species (Evenari, 1965). The first cases of negative photoblastism were described in 1903. We now know that both phenomena are widespread. Research has shown that light is required for optimum germination in a large majority of species, and that it increases the rate of germination in many others. This relation is par- ticularly true in grasses. In Rules for Testing Seeds (Association of Official Seed Analysts, 1960) light is specified as a requirement for more than 60 grass species. The germination requirements for alkali sacaton, or any other species of the genus, were not specified.

Comprehensive reviews of experimental work on light effects and germination have been made by Evenari (1956), Toole et al. (1957), and Hendricks and Borthwick (1963). Unfortunately, most of the research has been restricted to a very few species; there are innumerable papers dealing with light requirements of lettuce (Lactuca sativa) and Phacelia tanacetifolia. Sauer and Struik (1964) found that most kinds of crop seeds are indifferent to light, and that germination of many weed seeds is promoted by light. Germination of only a few species is known to be inhibited by light.

Apparently, very little research has been done on the effect of light on the germination of grasses. Cumming and Hay (1958) found that wild oats (Avena fatua) germinated only $10 \%$ when surface planted, but $65 \%$ when planted at a depth of 1 inch. Koller and Roth (1963) found that Panicum turgidum germinated best in darkness or when held for $24 \mathrm{hr}$ in darkness and in light thereafter. The presence of light at any time 
Table 1. Germination (\%) of alkali sacaton seeds exposed to light for the time specified after $30 \mathrm{~min}$ imbibition.

\begin{tabular}{|c|c|c|c|}
\hline \multirow{2}{*}{$\begin{array}{c}\text { Duration of } \\
\text { exposure to light }\end{array}$} & \multicolumn{3}{|c|}{$\begin{array}{c}\text { Germination at various } \\
\text { hours after start of imbibition }\end{array}$} \\
\hline & 24 & 48 & 72 \\
\hline None & $89 \mathrm{a}$ & $93 \mathrm{ab}$ & $96 \mathrm{a}$ \\
\hline Flash & $80 \mathrm{bcd}$ & $\overline{93 a}$ & $94 \mathrm{ab}$ \\
\hline 30 seconds & $81 \mathrm{bcd}$ & $94 a$ & $94 \mathrm{ab}$ \\
\hline 1 minute & $74 \mathrm{~cd}$ & $\overline{93 a b}$ & $\overline{93} \mathrm{ab}$ \\
\hline 5 minutes & $80 \mathrm{bcd}$ & $88 \mathrm{abc}$ & $91 \mathrm{bcd}$ \\
\hline 10 minutes & $83 \mathrm{ab}$ & $85 \mathrm{c}$ & $89 \mathrm{bcde}$ \\
\hline 20 minutes & $76 \mathrm{bcd}$ & $84 \mathrm{~cd}$ & $\overline{90} \mathrm{bcd}$ \\
\hline 30 minutes & $80 \mathrm{bcd}$ & $82 \mathrm{cde}$ & $87 \mathrm{abc}$ \\
\hline I hour & $79 \mathrm{bcd}$ & $88 \mathrm{abc}$ & $92 \mathrm{abc}$ \\
\hline 3 hours & $76 \mathrm{bcd}$ & $87 a b c$ & $92 \mathrm{abc}$ \\
\hline 5 hours & $82 \mathrm{bcd}$ & $87 \mathrm{bc}$ & $87 \mathrm{cde}$ \\
\hline 7 hours & 72de & $88 \mathrm{abc}$ & $89 \mathrm{bcd}$ \\
\hline 9 hours & $64 \mathrm{ef}$ & $82 \mathrm{cde}$ & 92abc \\
\hline 11 hours & $58 \mathrm{f}$ & $81 \mathrm{cde}$ & $93 \mathrm{ab}$ \\
\hline 13 hours & $60 \mathrm{f}$ & 77de & $94 \mathrm{ab}$ \\
\hline 15 hours & $23 \mathrm{~g}$ & $84 \mathrm{~cd}$ & $85 \mathrm{de}$ \\
\hline 17 hours & $20 \mathrm{~g}$ & $81 \mathrm{cde}$ & $82 \mathrm{ef}$ \\
\hline 19 hours & $18 \mathrm{gh}$ & $75 \mathrm{e}$ & $77 \mathrm{f}$ \\
\hline 21 hours & $19 \mathrm{gh}$ & $74 \mathrm{e}$ & $74 \mathrm{f}$ \\
\hline Continuous & $12 \mathrm{~h}$ & 54 & 59 \\
\hline
\end{tabular}

All values in columns not followed by the same letter are significantly different: all values in rows not underscored by the same line are significantly different (.05 level, Tukey procedure).

during the first 24 to $72 \mathrm{hr}$ of incubation did not inhibit germination if the seeds were held in darkness thereafter; in fact, this procedure actually hastened the start of germination.

Koller and Negbi (1959) found that germination of Oryzopsis miliacea was restricted by either constant light or darkness. The darkimposed restriction was broken by a single illumination period between 1 and 28 days after the start of imbibition. Although not so stated by the authors, it appears that $O$. miliacea requires light at some time during the incubation period for optimum germination.

Wright and Baltensperger (1964) found that germination of black grama grass (Bouteloua eriopoda) was as high in light as in darkness, but that germination was more rapid in darkness. all treatments, except the constant exposure, so that seeds received the specified exposure but once during the $72 \mathrm{hr}$ period. The study was terminated after $72 \mathrm{hr}$ because previous research has shown that, for all practical purposes, germination of alkali sacaton seeds is completed by this time.

\section{Results and Discussion}

The results show that germination of alkali sacaton is inhibited by light (Table 1). Short exposures primarily delayed germination, while the more lengthy exposures not only delayed but also reduced total germination.

After $24 \mathrm{hr}$, germination of seeds kept in darkness was significantly better than that of seeds which received light for all periods ranging from flash to continuous exposure with the exception of those exposed for $10 \mathrm{~min}$. The insignificant difference between darkness and $10 \mathrm{~min}$ exposure appeared to be due to shading of the petri dishes exposed $10 \mathrm{~min}$ by other dishes above and around them. Similarly, seeds exposed $1 \mathrm{~min}$ did not germinate significantly better during the first 24 hr than those exposed $10 \mathrm{~min}$. With the exception of seeds kept in darkness, seeds exposed $10 \mathrm{~min}$ were the only ones whose germination did not increase significantly from 24 to $48 \mathrm{hr}$ after the start of the study; in other words, this was the only treatment in which exposure to light did not significantly delay germination during the first $24 \mathrm{hr}$ after imbibition.

The same phenomenon was evident, and to a much greater extent, from the 48 th to the $72 \mathrm{nd}$ hr after start of imbibition: germination of seeds in darkness and exposed flash through $10 \mathrm{~min}$ did not increase significantly from 48 to 72 hr. This is understandable if we assume these short exposures were not sufficient to delay germination for more than $48 \mathrm{hr}$. We would then also have to assume that longer exposures would delay germination longer, with the amount 
of delay proportional to the length of exposure. This was not the case, however; germination of seeds exposed 20 and $30 \mathrm{~min}$ increased significantly from 24 to $48 \mathrm{hr}$, whereas germination of seeds exposed $10 \mathrm{~min}$ did not. Table 1 shows other such irregularities.

These apparent reversals of light effect may not have been real, but may have been due to shading of certain petri dishes by dishes on the shelves above and around them, or the result of other unmeasured sources of variation.

\section{Conclusions}

Light affects germination of alkali sacaton in the following ways:

1. Exposure of imbibed seeds for a few seconds to $9 \mathrm{hr}$ will delay germination of some of the seeds for more than $24 \mathrm{hr}$ but less than $48 \mathrm{hr}$.

2. Exposure for 9 through $13 \mathrm{hr}$ will delay germination of some of the seeds for more than $48 \mathrm{hr}$ but less than $72 \mathrm{hr}$.

3. Generally, exposure for more than $13 \mathrm{hr}$ not only delays but significantly reduces final germination.

\section{Literature Cited}

Association of Official Seed AnaLySTS. 1960. Rules for testing seeds. Proc. Ass. Offic. Seed Anal. 49(2):71.

Cumming, B. G., and J. R. Hay. 1958. Light and dormancy in wildoats (Avena fatua L.). Naturc 182: 609-610.

Evenari, M. 1956. Seed germination. In "Radiation Biology." McGrawHill Co., New York, Ed. by A. Hollaender, p. 519-549.

Evenari, M. 1965. Encyclopedia of plant physiology 25:804-847.

Hendricks, S. B., and H. A. BorthwICK. 1963. Control of plant growth by light. In "Environmental control of plant growth." $\Lambda$ cademic Press, New York. Ed. by L. T. Evans, p. 233-263.

KNIPE, O. D. 1967. Influence of temperature on the germination of some range grasses. J. Range Manage. 20:298-299.

KNIPE, O. D. 1969. Factors affecting the germination of alkali sacaton (Sporobolus airoides Torr.). Ph.D. Thesis, Univ. Ariz., Tucson.

Koller, D., And M. Negbi. 1959. The regulation of germination in Oryzopsis miliacea. Ecology 40:20-36.

Koller, D., AND N. Roth. 1963. Germination-regulation mechanisms in some desert seeds. VII. Panicum turgidum (Gramineae). Israel J. Bot. 12(2):64-73.

Sauer, J., And G. Struik. 1964. A possible ecological relationship between soil disturbances, light-flash and seed germination. Ecology 45: 884-886.

Toole, E. H., V. K. Toole, S. B. Hendricks, AND H. A. Borthwick. 1957. Effect of temperature on germination of light-sensitive seeds. Proc. Int. Seed Test. Ass. 22:196-204.

Wright, N., AND A. A. Baltensperger. 1964. Influence of temperature, light radiation, and chemical treatment on laboratory germination of black grama grass seed, Bouteloua eriopoda Torr. Crop Sci. 4:168-171. 